\author{
А.В. Достовалов ${ }^{1}$, А.А. Вольф ${ }^{1}$, С.А. Бабин ${ }^{1,2}$ \\ ${ }^{1}$ Институт автоматики и электрометрии Сибирского отделения РАН, \\ Новосибирск, Россия \\ ${ }^{2}$ Новосибирский государственный университет, Новосибирск, Россия

\section{ПОТОЧЕЧНАЯ ЗАПИСЬ ВБР ПЕРВОГО И ВТОРОГО ПОРЯДКА \\ ЧЕРЕЗ ПОЛИИМИДНОЕ ПОКРЫТИЕ ФЕМТОСЕКУНДНЫМ ИЗЛУЧЕНИЕМ С ДЛИНОЙ ВОЛНЫ 1026 НM}

\begin{abstract}
Представлены результаты фемтосекундной записи волоконных брэговских решеток (ВБР) первого и второго порядков через защитное пластиковое покрытие световода. В частности, записаны однородные решетки в нефоточувствительных световодах с полиимидной оболочкой SMP1500 (9/125) P и SMP1500SC (9/125) P (с чисто кварцевой сердцевиной), спектр отражения которых хорошо согласуется с расчетом. Показано, что данный метод позволяет также записывать суперструктурированные ВБР.
\end{abstract}

Ключевые слова: волоконная брэгговская решетка, фемтосекундная лазерная модификация показателя преломления, поточечная запись брэгговских решеток.

\author{
A.V. Dostovalov', A.A. Vol' ${ }^{1}$, S.A. Babin ${ }^{1,2}$ \\ ${ }^{1}$ Institute of Automation and Electrometry, Siberian Branch of Russian Academy \\ of Sciences, Novosibirsk, Russian Federation \\ ${ }^{2}$ Novosibirsk State University, Novosibirsk, Russian Federation
}

\title{
POINT-BY-POINT WRITING OF FIRST AND SECOND ORDER FBGS THROUGH POLYIMIDE COATING WITH FEMTOSECOND
}

\section{RADIATION AT 1026 NM}

There are presented the results on femtosecond writing of first and second order fiber Bragg gratings (FBG) through protective plastic coating of a fiber. In particular, there were written uniform gratings in non-photosensitive fibers with polyimide coating: SMP1500(9/125)P and pure-silica core SMP1500SC(9/125)P, with the reflectance spectra which are in good agreement with calculation results. It was demonstrated that the method can be used for writing of superstructure FBGs..

Keywords: fiber Bragg grating, femtosecond laser refractive index modification, point-by-point Bragg grating writing. 


\section{1. Введение}

Волоконные брэгговские решетки (ВБР) нашли широкое применение в сенсорных системах [1], волоконных лазерах [2], оптоволоконных системах связи [3]. Традиционным методом создания ВБР является технология УФ-записи [4], при которой периодическая модуляция показателя преломления возникает за счет помещения волоконного световода (ВС) в поле интерференционных полос УФ-излучения. В основе механизма изменения показателя преломления лежит поглощение УФ-излучения активными центрами, связанными с легирующими добавками в сердцевине ВС (см., например [5]). При этом фоточувствительность стандартных одномодовых ВС очень низкая, и для ее повышения обычно применяют предварительное насыщение световода водородом, увеличивающее концентрацию активных центров.

Альтернативным методом создания ВБР, бурно развивающимся в последнее время, является фемтосекундная запись [6], когда модуляция показателя преломления наводится за счет нелинейного поглощения в поле короткого импульса с большой интенсивностью. При этом модификация становится возможной и в нефоточувствительных материалах, в том числе в стандартных телекоммуникационных ВС без предварительного повышения фоточувствительности. Кроме того, применение поточечной схемы при фемтосекундной записи вместо интерференционной позволяет достаточно просто создавать ВБР с аподизированным профилем, решетки с чирпом (модуляцией частоты) и фазовыми сдвигами в структуре [7]. Исследования в данной области проводились в основном с использованием фемтосекундного титансапфирового (Ti:Sa) лазера (800 нм) либо его второй гармоники (400 нм) [8], а также фемтосекундного УФ-излучения [9]. Иттербиевые фемтосекундные лазеры (твердотельные или волоконные) с длиной волны 1020-1060 нм являются альтернативой широко распространенным Ti:Sa лазерам, поскольку параметры их излучения также позволяют реализовать режим нелинейного поглощения. Кроме того, данные лазеры имеют диодную накачку и вследствие этого обладают более простой конфигурацией и пригодны для долговременной стабильной работы в промышленных условиях. Однако применение фемтосекундного излучения с длиной волны $\sim 1$ мкм для записи ВБР остается слабо изученным и поэтому представляет собой актуальную задачу. 
Как уже отмечалось ранее, ВБР широко применяются в сенсорных системах благодаря ряду преимуществ: компактность, отсутствие восприимчивости к электромагнитным полям, способность прямого измерения таких физических параметров, как температура и деформация. Использование специализированных оптических ВС расширяет спектр применения датчиков на основе ВБР. Так, например, полиимидное защитное покрытие позволяет увеличить предел прочности ВC на растяжение и повышает стойкость ВС к высоким температурам; использование ВС с чисто кварцевой сердцевиной делает возможным применение волоконных датчиков в среде с повышенной концентрацией водорода [10]. Кроме того, полиимид обладает большей адгезией по сравнению с акрилатным покрытием, что важно для создания высокочувствительных датчиков деформации. Стандартная технология записи ВБР с помощью УФ-излучения требует удаления непрозрачного (для данных длин волн) пластикового защитного покрытия, что значительно снижает прочностные характеристики ВБР. Для фемтосекундного излучения с длиной волны 1 мкм защитное покрытие прозрачно, поэтому в этом случае возможна модификация показателя преломления ВС без удаления защитного покрытия. По этой причине запись ВБР через полиимидное покрытие также является актуальной задачей.

\section{2. Экспериментальная установка}

Исследования по созданию решеток показателя преломления выполнялись на установке прецизионной фемтосекундной модификации материалов, схема которой представлена на рис. 1. Излучение фемтосекундного лазера Light Conversion PHAROS 6W (длина волны второй гармоники 1026 нм, частотой повторения импульсов 1 кГц, длительность импульса на полувысоте 232 фс) через систему поворотных зеркал (M1-2, BS3) заводилось в микрообъектив 100X Mitutoyo Plan Apo NIR $\mathrm{HR}$ с большой числовой апертурой $\mathrm{NA}=0,7 . \mathrm{C}$ помощью системы ослабления пучка, состоящей из двух полуволновых пластинок и поляризатора (Р), устанавливался необходимый уровень энергии импульса. Перемещение образца производилось с применением системы высокоточных координатных столов Aerotech ABL1000; механический поворотный стол (ПС) позволял выставлять плоскостность поверхности образца по всей области сканирования. С помощью подсветки и ПЗС-матрицы выполнялась настройка положения области фокусировки внутри 


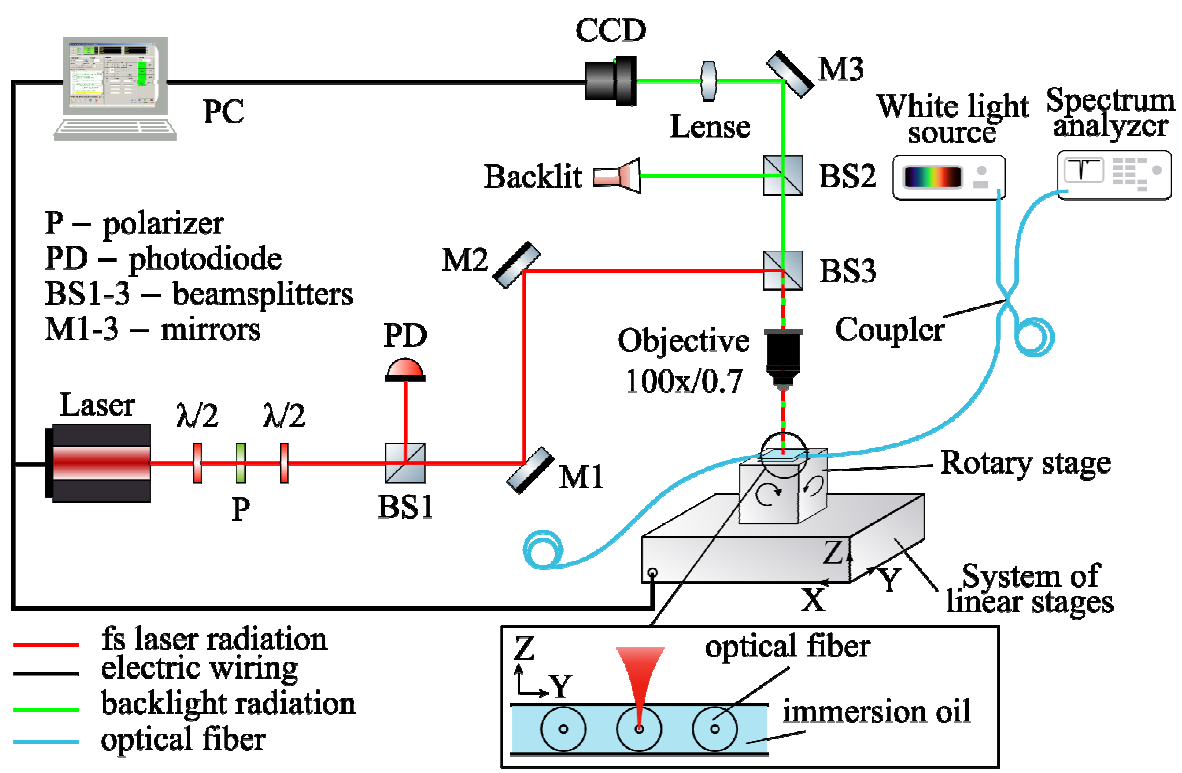

Рис. 1. Схема экспериментальной установки по фемтосекундной модификации прозрачных материалов

материала и проверялась плоскостность при перемещениях. Энергия импульсов лазерного излучения контролировалась высокочувствительным фотодетектором Ophir PD10-pJ (PD).

Для фокусировки излучения в сердцевину волоконного световода была выбрана схема, компенсирующая кривизну поверхности ВС (см. вставку на рис. 1). ВС располагался между двумя параллельными пластинами из плавленого кварца, пространство между которыми заполнялось иммерсионной жидкостью. Показатель преломления иммерсионной жидкости подбирался близким к показателю преломления оптического волокна для устранения преломления на границах.

Регистрация спектров волоконных решеток осуществлялась с помощью источника белого света Yokogawa AQ4305 и анализатора спектра Yokogawa AQ6370.

Сфокусированное высокоапертурным объективом в сердцевину движущегося ВС излучение лазера периодически модифицирует показатель преломления, при этом период решетки определяется выражением

$$
\Lambda_{\mathrm{FBG}}=\frac{v_{\mathrm{trans}}}{f_{\mathrm{rad}}},
$$


где $v_{\text {trans }}$ - скорость перемещения ВC; $f_{\text {rad }}$ - частота следования лазерных импульсов. Это означает, что период ВБР можно изменять, варьируя лишь скорость перемещения ВС при постоянной частоте повторения лазерных импульсов. С учетом этого выражение для резонансной длины волны ВБР $\lambda_{\text {FBG }}$ примет следующий вид:

$$
\lambda_{\mathrm{FBG}}=\frac{2 n_{\mathrm{eff}}^{\mathrm{core}} v_{\text {trans }}}{m f_{\mathrm{rad}}},
$$

где $m$ - дифракционный порядок решетки. Поскольку частота следования импульсов фиксирована, $f_{\mathrm{rad}}=1$ кГц, для создания решеток второго порядка $(m=2)$ с резонансной длиной волны $\lambda_{\text {FBG }} \approx 1550$ нм скорость перемещения ВC $v_{\text {trans }}$ в этом случае равна $1,07 \mathrm{Mm} / \mathrm{c}$, а для решеток первого порядка $-0,535 \mathrm{~mm} / \mathrm{c}$.

\section{3. Результаты}

На рис. 2 представлен спектр отражения решетки, записанной через полиимидную оболочку BC SMP1500(9/125)P (Fibercore Ltd.) с амплитудой отражения 86,5 \% и спектральной шириной 0,18 нм. Параметры ВС приведены в таблице. На рис. 3 представлено изображение, полученное с помощью дифференциальной интерференционно-контрастной микроскопии [11] данной ВБР. Параметры записи были следующие: энергия импульса $E_{p}=160$ нДж, $L_{\mathrm{FBG}}=11 \mathrm{Mм}, \Lambda_{\mathrm{FBG}}=1,07$ мкм (второй порядок, $m=2$ ).

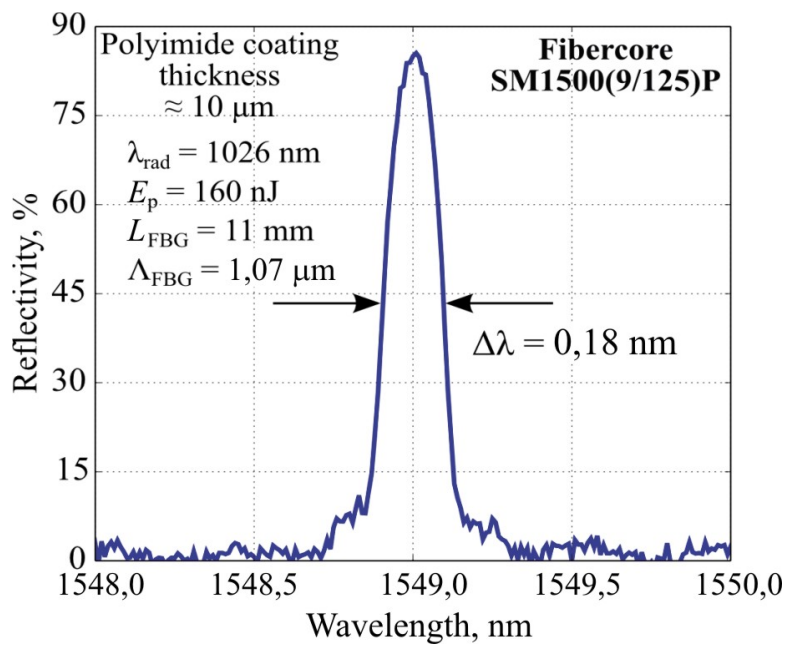

Рис. 2. Спектр отражения ВБР, записанной через полиимидное защитное покрытие в волоконном световоде SMP1500(9/125)P

(Fibercore Ltd.) 
Параметры световодов SMP1500(9/125)P и SMP1500SC(9/125)P

\begin{tabular}{|c|c|c|}
\hline \multirow{2}{*}{ Параметры } & \multicolumn{2}{|c|}{ Световод } \\
\hline & SM1500 (9/125) P & SM1500SC (9/125) P \\
\hline Рабочая длина волны, нм & \multicolumn{2}{|r|}{1550} \\
\hline Длина волны отсечки, нм & $1400-1500$ & $1190-1290$ \\
\hline Числовая апертура & \multicolumn{2}{|c|}{$0,13-0,15$} \\
\hline Диаметр поля моды, мкм & \multicolumn{2}{|c|}{9} \\
\hline Ослабление, дБ/км & $\leq 0,6$ & $\leq 0,8$ \\
\hline Предельное растяжение, \% & \multicolumn{2}{|c|}{2} \\
\hline Диаметр световода, мкм & \multicolumn{2}{|c|}{$125 \pm 2$} \\
\hline Диаметр защитного покрытия, мкм & \multicolumn{2}{|c|}{$145 \pm 5 \%$} \\
\hline Тип покрытия & \multicolumn{2}{|c|}{ полиимид } \\
\hline Максимальная температура, ${ }^{\circ} \mathrm{C}$ & \multicolumn{2}{|c|}{300 долговременно/400 кратковременно } \\
\hline
\end{tabular}

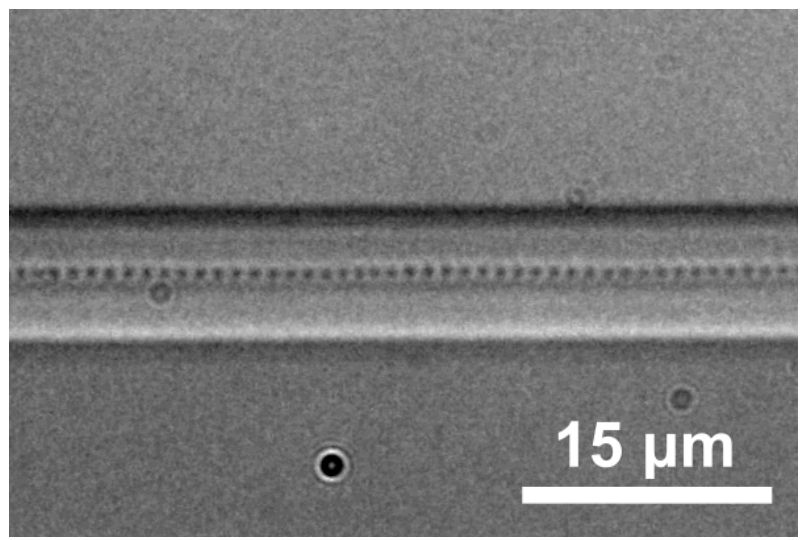

Рис. 3. Фрагмент брэгговской решетки, записанной в сердцевине волоконного световода SMP1500(9/125)P

На рис. 4 представлен спектр ВБР, записанной через полиимидное защитное покрытие в ВС с чисто кварцевой сердцевиной $\mathrm{SMP} 1500 \mathrm{SC}(9 / 125) \mathrm{P}$, с амплитудой пика отражения $51 \%$ и спектральной шириной 0,14 нм. На рис. 5 представлено DIC-изображение данной ВБР. Параметры записи были следующие: энергия импульса $E_{p}=160$ нДж, $L_{\mathrm{FBG}}=8 \mathrm{мM}, \Lambda_{\mathrm{FBG}}=1,07$ мкм (второй порядок, $m=2)$.

Необходимая разница $\Delta n$ между сердцевиной и оболочкой в ВС с чисто кварцевой сердцевиной достигается за счет допирования оболочки фтором, который уменьшает начальный показатель преломления кварцевой оболочки (рис. 6, б). 


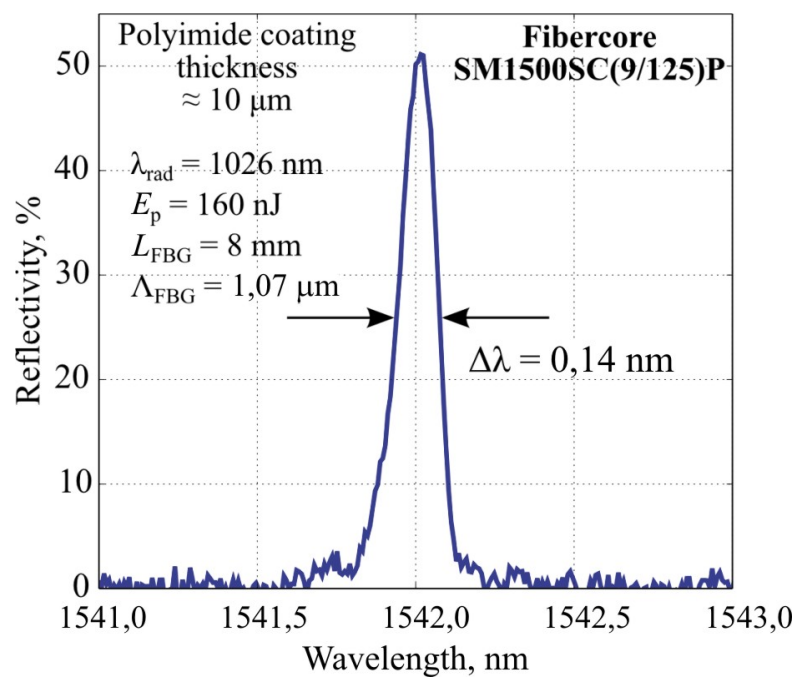

Рис. 4. Спектр отражения ВБР, записанной через полиимидное защитное покрытие в волоконном световоде с чисто кварцевой сердцевиной SMP1500SC(9/125)P (Fibercore Ltd.)

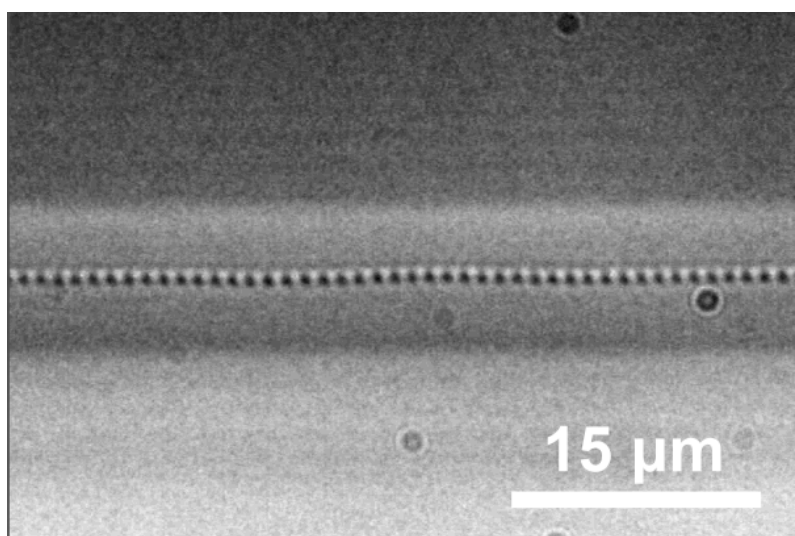

Рис. 5. Фрагмент брэгговской решетки, записанной в сердцевине волоконного световода SMP1500SC(9/125)P
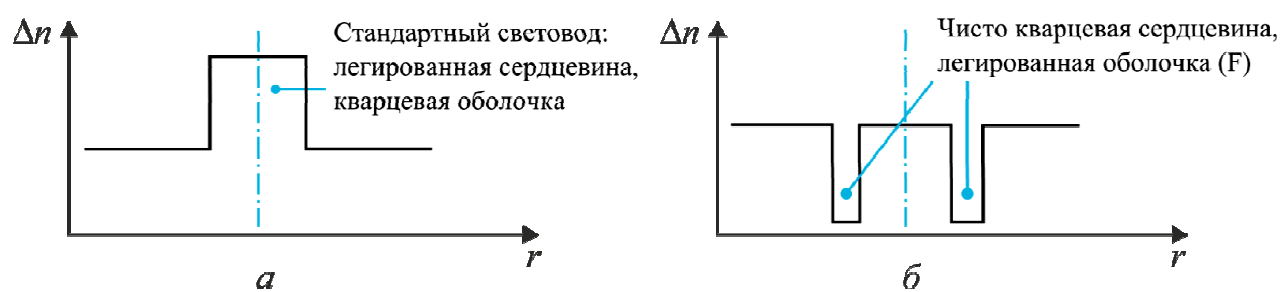

Рис. 6. Профиль показателя преломления стандартного световода $(a)$ и с чисто кварцевой сердцевиной (б) 
Поточечная технология записи ВБР фс излучением открывает возможности для создания ВБР со специфическими спектральными характеристиками или геометрическими параметрами (например, длина ВБР). Для получения высокого пространственного разрешения измерения физических величин требуется иметь ВБР как можно меньшего размера; с другой стороны, малая длина ВБР ограничивает максимальный коэффициент отражения при неизменной амплитуде модуляции показателя преломления, что также важно для адекватного опроса системы датчиков. При поточечной записи ВБР первого порядка существует проблема перекрытия областей модификации, что приводит к снижению видности решетки и, соответственно, к существенному снижению амплитуды отражения [12]. По этой причине в данном случае решетки второго порядка $(m=2)$ с периодом в 2 раза больше, чем у решеток первого порядка, имеют значительно большую амплитуду отражения. С другой стороны, очевидно, что при неизменных $\Delta n$ и $L_{\mathrm{FBG}}$ решетки второго порядка будут иметь гораздо меньшую амплитуду отражения по сравнению с решетками первого порядка, поэтому для достижения высоких коэффициентов отражения решеток второго порядка требуется увеличивать $L_{\mathrm{FBG}}$, что приводит к снижению пространственного разрешения измерений. Однако, как было показано в [13], «сильные» решетки первого порядка могут быть записаны при точном контроле энергии импульса, поскольку процесс модификации носит пороговый характер и при определенных значениях энергии импульса модификация происходит только в небольшой окрестности максимума гауссова распределения интенсивности, превышающей порог модификации. Таким образом, в данном случае перекрытия между областями модификации не происходит и решетки могут иметь значительную амплитуду отражения при небольших длинах ВБР.

На рис. 7 представлен спектр отражения ВБР первого порядка, записанной в волоконном световоде SMP1500 (9/125) Р через защитное покрытие. Параметры записи были следующие: энергия импульса $E_{p}=150$ нДж, $L_{\mathrm{FBG}}=2,7$ мм, $\Lambda_{\mathrm{FBG}}=0,535$ мкм (первый порядок, $\left.m=1\right)$. Амплитуда пика отражения при этом равна $69 \%$ при спектральной ширине 0,36 нм. Также на рис. 7 представлено сравнение экспериментального и расчетного спектров отражения данной ВБР, при расчетах использовалось значение $\Delta n=4,43 \cdot 10^{-4}$. Рисунок показывает, что расчетный спектр совпадает с экспериментальным достаточно хорошо, в том числе по спектральной ширине, положению и амплитуде боковых максимумов. 


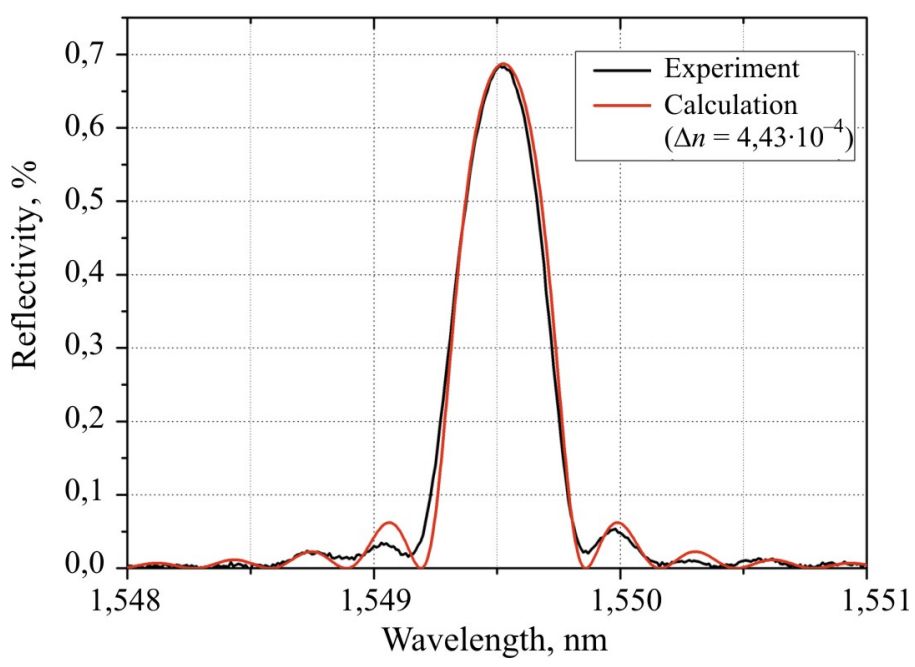

Рис. 7. Спектр ВБР первого порядка ( $L=2,7$ мм): эксперимент и расчет $\left(\Delta n=4,43 \cdot 10^{-4}\right)$

С целью дальнейшего повышения пространственного разрешения была записана ВБР с $L=1$ мм, при неизменных остальных параметрах эксперимента. Амплитуда пика отражения при этом равна $20 \%$ при спектральной ширине 0,87 нм. На рис. 8 представлено сравнение спектров отражения данной ВБР с расчетом в линейном (рис. $8, a$ ) и логарифмическом (рис. 8, б) масштабах. В данном случае $\Delta n=4,75 \cdot 10^{-4}$, что лишь на $7 \%$ отличается от предыдущего значения $\Delta n$ для ВБР длиной $L=2,7$ мм.

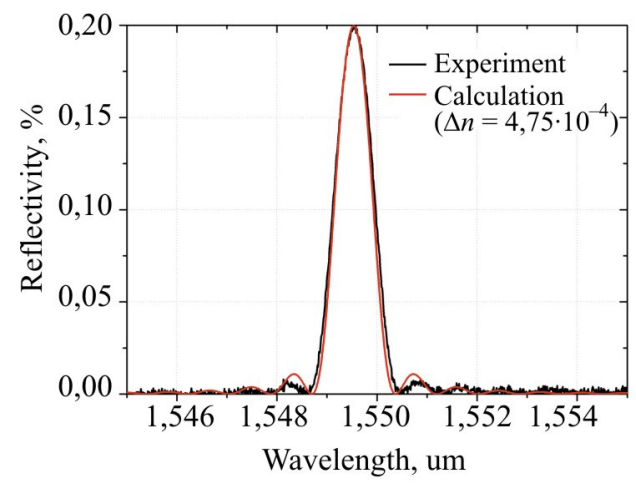

a

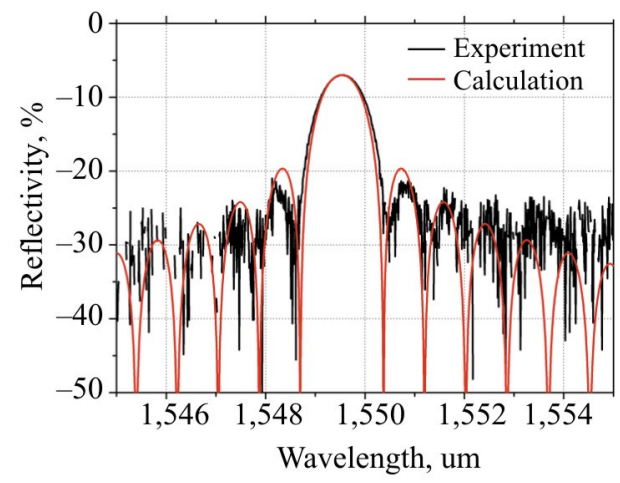

б

Рис. 8. Спектр ВБР первого порядка ( $L=1 \mathrm{mм})$ : эксперимент и расчет $\left(\Delta n=4,75 \cdot 10^{-4}\right)$ : линейный $(a)$ и логарифмический (б) масштабы 
Поточечная технология записи позволяет достаточно просто реализовать создание как однородных ВБР (у которых период не меняется вдоль ВБР), так и ВБР, имеющих неоднородное продольное изменение показателя преломления - так называемых суперструктурированных ВБР (с англ. superstructure $F B G$, сокращенно ССВБР - рис. 9), которые помимо основного периода $\Lambda_{\text {FBG }}$ также имеют модуляцию с периодом $\Lambda_{S}$, при этом в спектре отражения появляются дополнительные пики отражения на длинах волн [14], отстоящих от основного пика на величину $\Delta \lambda=\lambda_{\mathrm{FBG}}^{2} / 2 n \Lambda_{S}$, где $\lambda_{\mathrm{FBG}}-$ центральная длина волны отражения FBG, $n$ - эффективный показатель преломления, $\Lambda_{S}-$ период модуляции положения штрихов.

На рис. 10 представлен спектр ССВБР, записанной в волоконном световоде SMP1500(9/125)P через защитное покрытие со следую-

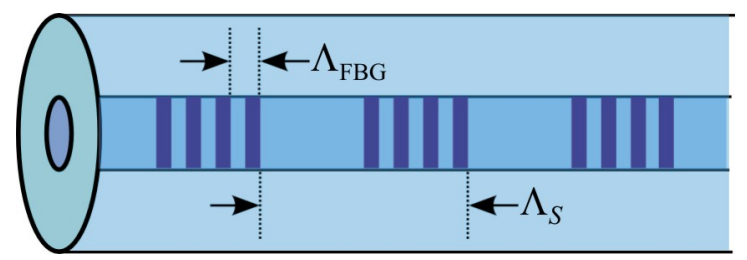

Рис. 9. Структура ССВБР

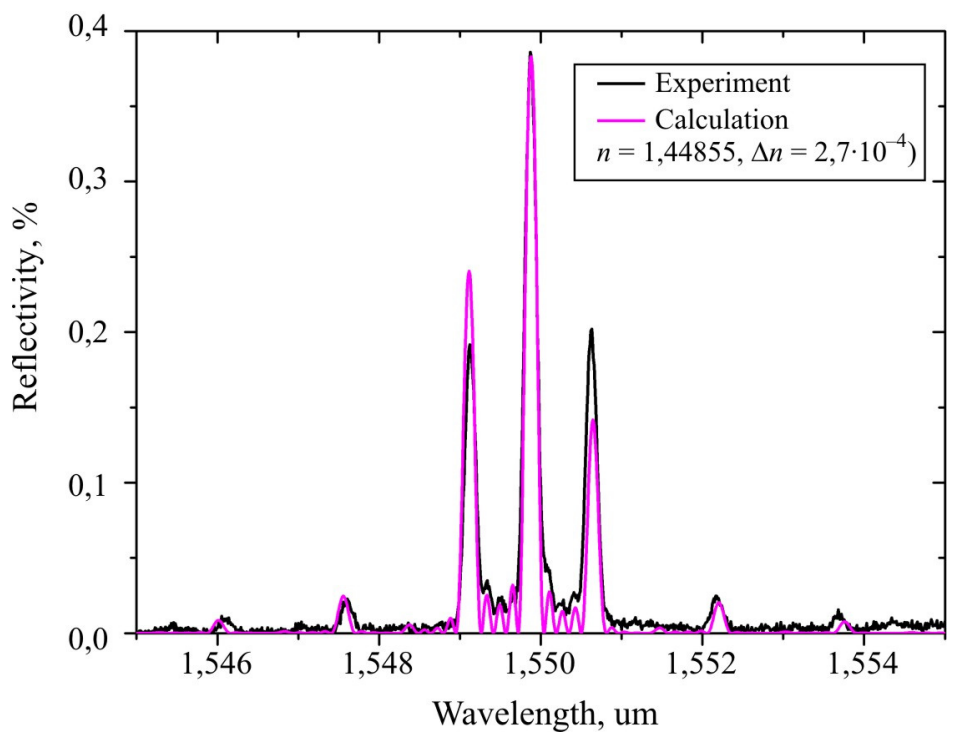

Рис. 10. Спектр ССВБР первого порядка $\left(L=5,35\right.$ мм, $\Lambda_{S}=1,07$ мм): расчет и эксперимент 
щими параметрами: $\Lambda_{\mathrm{FBG}}=535 \mathrm{Hм}, \Lambda_{S}=1,07$ мм, $L=5,35$ мм. Амплитуда пика отражения при этом равна 38,6 \% при спектральной ширине 0,17 нм. Исходя из представленной выше формулы значение $\Delta \lambda=(1550 \mathrm{Hм})^{2} /(2 \cdot 1,45 \cdot 1,07 \mathrm{Mм})=0,77$ нм, что близко к измеренным значениям $\Delta \lambda_{\text {right }}=0,75 \mathrm{Hм}, \Delta \lambda_{\text {left }}=0,76 \mathrm{Hм}$. На рис. 10 представлено сравнение с расчетным спектром ВБР с $\Delta n=2,7 \cdot 10^{-4}$. Как и в случае однородных ВБР, расчетный спектр суперструктурированной ВБР хорошо согласуется с экспериментальным по параметрам основного и дополнительных пиков.

\section{4. Выводы}

В данной работе продемонстрирована поточечная запись ВБР второго порядка фемтосекундным излучением с длиной волны 1026 нм через защитное покрытие волоконного световода SMP1500(9/125)P и ВC с чисто кварцевой сердцевиной SMP1500SC(9/125)P. Показано, что оно позволяет также записывать однородные и суперструктурированные ВБР первого порядка через защитное покрытие, в том числе полиимидное. Теоретические расчеты спектров хорошо согласуются с полученными экспериментальными результатами.

Полученные ВБР могут применяться в качестве чувствительных элементов сенсорных систем с высоким пространственным разрешением с большими рабочими диапазонами как по температуре, так и по деформации, расширенными в сравнении с ВБР, созданными по технологии УФ-записи. Кроме того, ВБР в световоде с чисто кварцевой сердцевиной могут успешно использоваться для долговременного мониторинга в жестких внешних условиях повышенной концентрации водорода и наличии повышенного радиационного фона. Суперструктурированные ВБР также могут применяться в сенсорных системах мониторинга для одновременного измерения температуры и деформации [15]. Кроме того, узкополосные ВБР, записанные через защитную оболочку как в пассивных, так и в активных (легированных редкоземельными элементами) световодах, будут обладать повышенными эксплуатационными характеристиками при использовании в качестве зеркал мощных волоконных лазеров.

Работа выполнена за счет гранта Российского научного фонда (проект № 14-22-00118). 


\section{Список литературы}

1. Optical Fiber Sensor Technology / ed. by K.T.V. Grattan, B.T. Meggitt. - Boston, MA: Springer US, 2000.

2. Kashyap R. Fiber Bragg Gratings. - Academic Press, 1999.

3. Othonos A., Kalli K. Fiber Bragg gratings. - Boston: Artech House, 1999.

4. Photosensitivity in Optical Fibers / K.O. Hill, B. Malo, F. Bilodeau [et al.] // Annu. Rev. Mater. Sci. - 1993. - Vol. 23, no. 1. - P. 125-157.

5. Волоконные решетки показателя преломления и их применения / С.А. Васильев, О.И. Медведков, И.Г. Королев [и др.] // Квантовая электроника. - 2005. - Т. 12. - С. 1085-1103.

6. Femtosecond pulse written fiber gratings: a new avenue to integrated fiber technology / J. Thomas, C. Voigtländer, R.G. Becker [et al.] // Laser Photon. Rev. - 2012. - Vol. 6, no. 6. - P. 709-723.

7. Point-by-point written fiber-Bragg gratings and their application in complex grating designs / G.D. Marshall, R.J. Williams, N. Jovanovic [et al.] // Opt. Express. - 2010. - Vol. 18, no. 19. - P. 19844-59.

8. Fabrication of a long-period grating in a fibre by second-harmonic radiation from a femtosecond Ti:sapphire laser / K.A. Zagorul'ko, P.G. Kryukov, Y. V. Larionov [et al.] // Quantum Electron. - 2001. - Vol. 31, no. 11. P. 999-1002.

9. Inscription of fiber Bragg gratings by ultraviolet femtosecond radiation / A. Dragomir, D.N. Nikogosyan, K.A. Zagorulko [et al.] // Opt. Lett. 2003. - Vol. 28, no. 22. - P. 2171-2173.

10. Yamamoto Y., Sasaki T., Taru T. Water-free pure-silica-core fibre and its stability against hydrogen ageing // Electron. Lett. - 2004. - Vol. 40, no. 22. - P. 1-2.

11. Murphy D. Differential interference contrast (DIC) microscopy and modulation contrast microscopy // Fundamentals of Light Microscopy and Digital Imaging. - New York: Wiley-Liss, 2001. - P. 153-168.

12. Direct writing of fibre Bragg gratings by femtosecond laser / A. Martinez, M. Dubov, I. Khrushchev [et al.] // Electron. Lett. - 2004. Vol. 40, no. 19. - P. 19-20.

13. Point-by-point inscription of first-order fiber Bragg grating for C-band applications / Y. Lai, K. Zhou, K. Sugden [et al.] // Opt. Express. 2007. - Vol. 15, no. 26 . - P. 18318-18325. 
14. Eggleton B., Krug P. Long periodic superstructure Bragg gratings in optical fibres // Electron. Lett. - 1994. - Vol. 30, no. 79. - P. 1620-1622.

15. Guan B., Tam H. Simultaneous strain and temperature measurement using a superstructure fiber Bragg grating // IEEE Photonics Technol. Lett. - 2000. - Vol. 12, no. 6. - P. 675-677.

\section{References}

1. Optical Fiber Sensor Technology. Ed. by K.T.V. Grattan, B.T. Meggitt. Boston, MA: Springer US, 2000.

2. Kashyap R. Fiber Bragg Gratings. Academic Press, 1999.

3. Othonos A., Kalli K. Fiber Bragg gratings. Boston: Artech House, 1999.

4. Hill K.O., Malo B., Bilodeau F. [et al.] Photosensitivity in Optical Fibers. Annu. Rev. Mater. Sci., 1993, vol. 23, no. 1, pp. 125-157.

5. Vasil'ev S.A., Medvedkov O.I., Korolev I.G. [et al.]. Volokonnye reshetki pokazatelia prelomleniia i ikh primeneniia [Fiber grating of refractive index and its application]. Kvantovaia elektronika, 2005, vol. 12, pp. 1085-1103.

6. Thomas J., Voigtländer C., Becker R.G. [et al.]. Femtosecond pulse written fiber gratings: a new avenue to integrated fiber technology. Laser Photon. Rev., 2012, vol. 6, no. 6, pp. 709-723.

7. Marshall G.D., Williams R.J., Jovanovic N. [et al.]. Point-by-point written fiber-Bragg gratings and their application in complex grating designs. Opt. Express, 2010, vol. 18, no. 19, pp. 19844-19859.

8. Zagorul'ko K.A., Kryukov P.G., Larionov Y.V. [et al.]. Fabrication of a long-period grating in a fibre by second-harmonic radiation from a femtosecond. Quantum Electron, 2001, vol. 31, no. 11, pp. 999-1002.

9. Dragomir A., Nikogosyan D.N., Zagorulko K.A. [et al.]. Inscription of fiber Bragg gratings by ultraviolet femtosecond radiation. Opt. Lett., 2003, vol. 28, no. 22, pp. 2171-2173.

10. Yamamoto Y., Sasaki T., Taru T. Water-free pure-silica-core fibre and its stability against hydrogen ageing. Electron. Lett., 2004, vol. 40, no. 22 , pp. 1-2.

11. Murphy D. Differential interference contrast (DIC) microscopy and modulation contrast microscopy. Fundamentals of Light Microscopy and Digital Imaging. New York: Wiley-Liss, 2001, pp. 153-168.

12. Martinez A., Dubov M., Khrushchev I. [et al.] Direct writing of fibre Bragg gratings by femtosecond laser. Electron. Lett., 2004, vol. 40, no. 19, pp. 19-20. 
13. Lai Y., Zhou K., Sugden K. [et al.]. Point-by-point inscription of first-order fiber Bragg grating for C-band applications. Opt. Express., 2007, vol. 15 , no. 26 , pp. 18318-18325.

14. Eggleton B., Krug P. Long periodic superstructure Bragg gratings in optical fibres. Electron. Lett., 1994, vol. 30, no. 79, pp. 1620-1622.

15. Guan B., Tam H. Simultaneous strain and temperature measurement using a superstructure fiber Bragg grating. IEEE Photonics Technol. Lett., 2000, vol. 12, no. 6, pp. 675-677.

Получено 25.11.2014 